\title{
A dangerous triangularization of conflicting values in academic publishing: ORCID, fake authors, and risks with the lack of criminalization of the creators of fake elements
}

\author{
Jaime A. Teixeira da Silva ${ }^{a}$
}

\begin{abstract}
The mainstream publishing establishment is under attack from multiple known and unknown threats. This is neither hyperbole nor fantasy. Some academics might consider that the main threat in open access publishing lies with "predatory" journals or publishers, but this is not necessarily the case because such entities are not always easy to distinguish clearly from veritable scholarly journals or publishers. Moreover, there is a gray zone that may involve entities with both predatory and exploitative qualities. Current submission systems are not fail-safe because they allow unscholarly or fraudulent individuals, with real or falsified emails, to register and abuse them, for example for submitting fake research or falsified peer reports. Moreover, although the author identification and validation tool ORCID is useful, recent evidence suggests that it is imperfect and is providing a platform for fake and fraudulent elements to "validate" themselves. Ten examples of nonsense "fruit"-based ORCID accounts are provided. This toxic mixture of fake elements and an increasingly widely adopted (and abused) authorship validation tool aimed at fortifying integrity in academic publishing is allowing some fake authors to exist and function with limited ethical or legal repercussions. A continuation of this state may gradually erode some of the publishing landscape if serious action is not taken. The creation of fake papers by fake authors may eventually trickle down into valid literature, by virtue of the fact that cited literature cannot, due to human and technical limitations, be completely vetted, even in peer review. The integrity of valid scholarly venues is by association at risk unless suitable, strict and ethically and legally enforceable preventative measures are implemented.
\end{abstract}

Keywords: criminal; fake elements; indexing; metrics; online submission systems; perverse incentives; ORCID; stings

\section{The rise of fake elements in academic publishing}

Academic publishing, especially open access publishing, is being threatened by several fake elements such as fake authors/identities, papers, and emails, all of which constitute the core fabric of publishing (Teixeira da Silva, 2017a). Despite this,

a. Independent researcher, P. O. Box 7, Miki-cho post office, Ikenobe 3011-2, Kagawa-ken, 761-0799, Japan. jaimetex@yahoo.com there appear to be denialists, including among the status quo, who either do not want to see the rise in threats, who are oblivious of how such threats will eventually affect their own journals for which they are attempting to create corrals of "good", scholarly or safe literature, who are down-playing the risks, or who are not transmitting information about the risks to academics and may be concealing the truth, perhaps to avoid panic among the academic populace. Absent a base of trust, which can no longer be taken for granted, there is thus the need to raise awareness, wherever possible, to allow academics, editors, journals and publishers 
to try and protect themselves against actual or potential threats to their publishing operations.

Fake (depending on the degree of fake, which could also be fraudulent in extreme cases) elements may permeate publishing venues that are traditionally thought to be impermeable to fraudulent, bad or fake science, i.e., pseudo-science. Fake peer review, which involves the manipulation of the identities of "peer reviewers" by authors to create outcome-friendly (but non-existent) "peers", or editors that have succumbed to a lack of integrity by skipping a peer review step despite claiming that papers have been peer reviewed, may lead to the production of pseudo-science that, in a worstcase scenario, lead to retractions, ultimately eroding trust in that journal, the scientific literature, and more broadly, in academic publishing's gold quality tool, peer review (Rivera and Teixeira da Silva, 2021). Fake science that eventually permeates society will breed mistrust in science (Hopf et al., 2019). Some scholars are calling for the criminalization of fake elements such as falsified data or the fraudulent manipulation of the peer review process (Dal-Ré et al., 2020). However, such a serious decision needs to carefully deliberate the weight of the infraction, intentions, context and circumstances so as not to violate any rights. International cases might be difficult to resolve.

Given the strong financial motivations for publishing in ranked and metricized journals, much academic work emerging from China has been shown to contain fraudulent elements, but in the face of academic fraud emerging from that country, its cash-based reward system is now being banned (Malapaty, 2020). A meta-analysis of over 500 retractions of papers affiliated with hospitals in mainland China revealed that many of those papers, which were indexed in PubMed or Clarivate Analytics' Web of Science (WoS), were associated with fraud and fabrication, and also the use of third party services, such as paper mills (Zhao et al., 2021). Paper mills ${ }^{1}$ provide paid-for services to au-

1. Many of the grass-roots efforts, made by named and anonymous individuals and/ or groups, have been documented on the thors, and the product of that service is a paper that itself may be created by the paper mill, or aspects of the paper that may be fabrications, i.e., scientific exploration that was not conducted by the authors themselves (Byrne and Christopher, 2020; Rivera and Teixeira da Silva, 2021). Such paper mills act unethically by creating pseudo-science, i.e., science that is concocted, and not created through discovery, while the authors act unethically not only by ordering a paper, ready-made as easily as one might order a pizza, but even more so because their claims of originality when they submit readymade papers are evidently false. To the author's knowledge, there is no tool currently available to detect whether a paper is a product of a paper mill, and this fact, if discovered, usually only arises from the product of post-publication scrutiny.

\section{The abuse of ORCID in the fake author and paper movement}

To offer clearer insight into the range of problems associated with the issue of "fake", I turn to an example of the now-retracted "Bo Liu" et al. paper (Liu et al., 2020) that was published in Elsevier's Scopus-indexed The International Journal of Biochemistry \& Cell Biology (IJB\&CB) (Teixeira da Silva, 2020a). That journal, despite having claimed peer review, a "respectable" Clarivate Analytics' journal impact factor (IF), and indexed on Scopus, WoS and PubMed, was unable to detect, or offer protection against, the academic deceit of a new academic threat, paper mills (Teixeira da Silva, 2021a). The paper had a bevy of infractions, including the misappropriation of academics' identities and affiliations, without approval. Of greater concern, the identity of "Bo Liu" remains elusive, and the author disambiguation tool, Open Researcher and Contributor ID (ORCID), is unable to correctly or accurately identify the validity of one or more academics and/or their affiliations on that now-retracted paper. A double layer of abuse has now emerged: abuse of ORCID by those using paper mills to publish fraudulent and

Leonid Schneider blog, and offer more background into this phenomenon: https:// forbetterscience.com/?s=paper+mill 
fake science (Teixeira da Silva, 2021b).

Of what value is ORCID if it cannot accurately identify an academic, and thus offer a layer of ethical protection and author validation (i.e., integrity) to a journal or publisher? In this case, ORCID failed a core mission. Another small analysis revealed, through a random search, 35 preposterous examples of "researchers" with an ORCID (Teixeira da Silva, 2021c). Such cases should serve as red flag alerts and warning signs, not necessarily to drive academia into a panic, frenzy, or state of paranoia, but to indicate that, by association (citations, same journal, or publisher, shared indexing agency, etc.), the threat to one entity can easily become a threat to other academics and publishers if left uncontrolled.

ORCID (the organization), many academics and the publishing establishment that are loudly touting ORCID as a useful tool, appear to be in denial about the failure of this tool, or are underestimating the academic threat of "ghost" ORCID accounts, the use of ORCID to commit academic fraud, and the establishment of ORCID accounts for and/or by fake individuals (Teixeira da Silva, 2020b, 2020c). A Springer Nature journal, Journal of Nanoparticle Research, with an IF and indexed, became the victim of a network of fake guest editors with fake identities and emails, who tricked the journal's editors into publishing a special issue with equally fake papers, or with fake or fraudulent elements in them (Pinna et al., 2020). The unsuspecting editors, who most likely placed too much faith in trust and in the robustness of a fallible publication ecosystem, noted that they had "probably" been careless. At the same time, they are also victims of increasing fraudulent targeting of special issues (Trapp, 2020). As another two recent examples, in these cases not linked to ORCID but for which ORCID would have been useful had it been used, a fraudulent entity impersonated a guest editor of a Taylor \& Francis journal, Behaviour \& Information Technology, leading to the retraction of at least 10 papers ${ }^{2}$, while a second fraudulent impersonator or impostor of a Canadian researcher using a fake email address created a fake paper

2. https://retractionwatch.com/2021/06/18/ galling-journal-scammed-by-guest-editorimpersonator/ using their name and affiliation. ${ }^{3}$ In the latter case, there are only three realistic steps possible to deal with this situation: 1) if the journal leaves the paper intact, they reward the criminal entity behind the fake operative; 2 ) if they retract the paper and leave it with a "retracted" watermark, they unfairly penalize the real author; 3 ) if they silently remove the paper (silent retraction) (Teixeira da Silva, 2016a), they act in an unscholarly or predatory manner. In the Jamie Burr case, had the editors screened the ORCID database, they would have found an ORCID account for "Jamie F. Burr" ${ }^{4}$, the real author who was fraudulently impersonated and who was the victim of identity theft.

All academics, editors and journals should heed these warning signs and pay close attention to these examples as more and more academics are forced to sign up and use (i.e., mandatory requirement) ORCID, for example for the submission to a journal, and as more fake elements begin to populate the ORCID platform (Teixeira da Silva, 2020d) and other scholarly databases (Menon and Khosravi, 2019). In "predatory publishing", both fake open access and subscription journals attract authors who are under pressure to publish, and this sometimes involves the use of fake metrics, which tend to involve similar names to the IF, to lure them (Dadkhah et al., 2016; Samuel and Aranha, 2018). Similarly, fake academics that seek tools to legitimize their fraud may employ ORCID as one method of deception.

\section{Predatory publishing is a destabilizing force in academic publishing}

Fraud and deceit, which are typically associated with "predatory publishing", especially in open access, are massive destabilizing forces in academic publishing because they threaten the status quo's "control of scholarly communication" (Noga-Styron et al., 2016) by creating and providing an alternative and parallel academic (publishing) and financial (e.g., article processing charges) market.

3. https://retractionwatch.com/2021/06/23/ an-exercise-in-frustration-a-researcher-isimpersonated/

4. https://orcid.org/0000-0002-5449-3352 
Consequently, in a publishing landscape that has now largely become established on a principle of gaming (i.e., based on the gaming/abuse of metrics such as IF, ranking, prestige and other unscholarly or non-academic parameters) (Oravec, 2019), predatory and exploitative practices might be difficult to distinguish, or they may even go hand in hand (Teixeira da Silva et al., 2019). For example, how does one distinguish an indexed journal that claims to be peer reviewed but that then fails to verify the validity of its authors' identities from a non-indexed journal that carries out no peer review and also fails to detect fake authors? On what basis or classification system does one differentiate them? And why should the indexed journal be considered to be non-predatory and a "victim" while the non-indexed journal is considered to be predatory (Teixeira da Silva, 2021d)?

It is thus no surprise that a sector of the academic population will abuse the academic scaffold that was established by the publishing community (i.e., publishers and associates), to seek personal and professional gains to advance their own agendas. Blame should be equally assigned to 1) publishers who provide insecure platforms for abuse; 2) academics (or others) who abuse those platforms; 3) academic institutes that rely blindly on metrics to guide their notion of "quality" or on publishers to guide them, while allowing academics excessive freedom of choice; 4) funders who do not establish their own strict publishing "quality" criteria for academics they fund. Collectively, perverse incentives, exploitative elements, and insufficiently secure or robust publishing protective measures will undoubtedly see a rise in fraud (Mavrogenis et al., 2018).

As a result, two broad camps (which may or may not be linked or coordinated groups, and which may or may not be well funded) of false/fake in academia seem to have emerged. In group 1, authors attempt to give the impression of being legitimate, including targeting "traditionally safe" and reputable (e.g., with an IF or on PubMed, WoS, etc.) publishing venues, but they employ misconduct by abusing publishing's weaknesses to advance their careers (Harvey, 2020). In group 2, individuals or masked organizations pose as authors or academics, but employ fake, false or non-existent elements (names, emails, affiliations, etc.) to advance a purpose or ideology. One possible candidate for this category would be Alireza Heidari, whose name may or may not be real, but an individual (or group) that has built an entire platform of "papers" using a fake affiliation, California South University, which does not exist ${ }^{5}$, but which continues to maintain an entire website. ${ }^{6}$ In the case of Heidari, ORCID ${ }^{7}$ and Google Schol$\operatorname{ar}^{8}$ accounts remain intact, despite an alert having been sent to these organizations, although the ResearchGate profile has disappeared (Fig. 1). Similar to the population of ORCID by fake or fictitious "authors", the existence of a Publons ResearcherID for Heidari ${ }^{9}$ also calls into question the legitimacy of academics on Publons (Teixeira da Silva, 2020e; Teixeira da Silva and Al-Khatib, 2021).

In the latter case (group 2), one such dishonest tactic is to "sting" (i.e., trick or deceive) a journal by exposing its false claim of "peer-review", thereby shaming it and portraying it as "predatory". However, in order to achieve their objective, group 2 individuals employ dishonest, unethical, even fraudulent tactics, to achieve their means (Teixeira da Silva, 2021e). Criteria used to classify a journal or publisher as "predatory" are unspecific, or may carry biases or lack of specificity (Tsigaris and Teixeira da Silva, 2021), similar to blacklists of socalled "predatory" journals or publishers (Teixeira da Silva and Tsigaris, 2018, 2020).

\section{Calls to criminalize science fraud, and risks to in- dexes and ethics}

In this complex mixture of misconduct and equally dishonest tactics to expose fraud, a highly contrasting set of attitudes has emerged in response

5. https://blogs.sciencemag.org/pipeline/ archives/2018/02/21/down-the-rabbit-holewith-alireza-heidari

6. http://calsu.us/index.php/member/prof-dralireza-heidari/

7. https://orcid.org/0000-0003-2655-133X

8. https://scholar.google.com/

citations?user $=2 \mathrm{yKnXwYAAAAJ \& hl=en}$

9. https://publons.com/researcher/1293511/ scholar-researcher/ 
to both groups of fake. Some energy and attention is being devoted to criminalize the former camp of deceitful individuals (e.g., Dal-Ré et al., 2020), simply because group 1 individuals can more easily be identified (e.g., clear identity and association with an institution) and thus be held accountable. Yet, almost no action is being taken to deal with, or find solutions to, the latter group 2 of deceitful individuals because the entities that hide behind masks cannot - for now - be identified. If legitimacy is given to fake elements, even those hiding behind anonymous and pseudonymous entities (Teixeira da Silva, 2017b), how does academia differentiate those that claim to be working for a "greater" good, and should they be allowed ethical and criminal exceptionalism based exclusively on their claimed moral authority, or interaction with the ethical elite, using social media as their preferred medium of communication (Teixeira da Silva and Dobránszki, 2019)? For this reason, criminal forensics is now needed in academic publishing to be able to trace the digital fingerprints of such fakes.

Occasionally, fake elements appear in indexed or ranked journals, publishers or platforms, like PubMed, Scopus or WoS, and these may ultimately undermine the credibility of databases, indexing platforms (e.g., PubMed; Teixeira da Silva, 2021f), or legitimate scholarly journals or publishers, leading to a gray zone of journals that may have several weakly scholarly characteristics, but not necessarily predatory ones (Teixeira da Silva, 2020f). Some entities that are blacklisted (e.g., by Cabell's) may claim to be associated with reputable "ethics" organizations (e.g., COPE, ICMJE), appear on reputable databases (e.g., PubMed, Scopus, or WoS), or may even be whitelisted (e.g., on DOAJ). However, those claims may be false, and it is incumbent upon academics to complete their own independent investigation about the veracity of claims, and to, as best as possible, assess whether the structural and publishing elements indicated on a journal or publisher's website are valid (Hillman and Baydoun, 2019). Sadly, far too many academics are too busy - or too lazy - to verify such aspects pertaining to quality and prefer to rely on third party services (e.g., Cabell's), or whitelists or blacklists, even if they are imperfect (Dony et al.,
2020), to base their decisions on where to submit a paper. Commercial publishers and associated cottage industry gamers and players take advantage of academics' business or laziness to establish brands and services of no intrinsic academic value, and that serve merely to market a tool (e.g., ORCID), or a platform (e.g., databases, blacklists, etc.). Thus, there are currently no clear or easy solutions because "predatory publishing" entities can appear within a gray zone of predatory and exploitative behavior, ranging between dishonesty and criminality (Umlauf and Mochizuki, 2018).

To untrained and unsuspecting eyes, fake authors may in fact appear legitimate. However, in several cases, these might not necessarily be fake (i.e., concocted) names, but might also be hijacked names (e.g., of retired or deceased academics). Independent of the fake or non-existent entity that might also be associated with a fake academic institution, fabricated email and/or a "ghost" ORCID account, those elements were intentionally created by a real person or group. Currently, the identity of the creators of fake entities are unclear, but their existence is a risk and threat at many levels within legitimate scholarly venues: the stability, veracity and credibility of the entire publishing framework is threatened; metrics and indexing are disrupted because illegitimate papers might be cited by legitimate scholarly journals and then indexed in reputable databases; they may constitute a health risk if information in fake papers covers health issues, such as COVID-19, and if such information is then used for policy-making (Teixeira da Silva, 2020g). Fake, pseudo-scientific, or fraudulent health information lies within a wider culture of "fake", including fake news, that abounds in modern society (Collins and Bassat, 2018), and may be an ill that is difficult to expunge, provided that there are economic and other incentives and benefits (Harvey, 2020).

\section{Action is needed now}

Very importantly, the entities (individuals or groups) that create fake authors engage in dishonest, predatory and deceitful behavior, which may be criminal depending on the level of falseness in- 
volved (e.g., False Statements Act), are able to survive in the current publishing infrastructure partly because transnational prosecution is expensive and difficult (Manley, 2019), and since publishers' online submission systems are not designed to deal effectively with the detection and management of these wide-ranging types of fraud. Journals need stronger protective measures, including more stringent author and institutional verification upon submission, although this comes with the risk of further "militarizing" academic publishing (Teixeira da Silva, 2016b), advanced techniques such as Benford's Law to detect fabricated datasets (Horton et al., 2020), forensic tools are needed to detect fraudulent elements in papers (Utakrit and Wuttidittachotti, 2021; Wjst, 2021), while a legal framework for a journal or publisher is needed to seek criminal prosecution if they are defrauded, not unlike legal powers in the face of copyright infringement (Vasiu and Vasiu, 2019). While large commercial publishers might have the resources to establish such an infrastructure, smaller journals might not.

For example, image forensic tools are still experimental, those that exist might be expensive or require technical training, and for a small journal, this might present a costly investment. Therefore, a small journal's best defenses remain some of the most basic and obvious ones: 1) screen authors of a paper soon after submission and verify the authenticity of author identity, for example, comparing against other of the authors' papers, doing simple cross-checks to see if emails match; 2) where data is involved, seek to request the submission of raw data with submission; 3 ) have a robust set of ethics guidelines in place, with a clear notice that an institutional ethical investigation will accompany the detection of any suspicious activity that violates any stated ethics codes.

Finally, editors who mandate ORCID from submitting, corresponding, or all authors as a prerequisite for submission to their journal need to be conscientious of the fact that this "integrity" tool for author identification and authentication is imperfect. Even though Kim and Owen-Smith (2021) heaped praise on ORCID, it is unclear how their large-scale meta-analysis of the ORCID database was unable to detect the accounts of fake authors, fraudulent authors, or false positives (i.e., identities that claim to be authors, but which are something or someone else, e.g., 35 cases reported in Teixeira da Silva (2021c). To fortify the concerns, a search for "fruit", including for specific fruits, yielded a fruitful set of results (Table 1). Those authors who currently have an ORCID, or those editors forcing authors to obtain one, need to begin to consider that they are sharing an author ID tool with these same nonsense, fake, or fraudulent elements.

Figure 1. The ResearchGate account of Alireza Heidari, who employs a fake affiliation in his social media profiles and research papers, California South University, no longer exists: https:// www.researchgate.net/profile/Alireza_Heidari12. Screenshots for (A) and (B) taken on May 26 and June 2, 2020, respectively, during which period the number of "papers" rose from 156 to 183. The internet archive (Wayback Machine) has a single entry, for November 1, 2020, showing 194 "papers" (screenshot taken on June 24, 2021): https://web. archive.org/web/20201101114444/https://www.researchgate.net/profile/Alireza_Heidari12 (C).

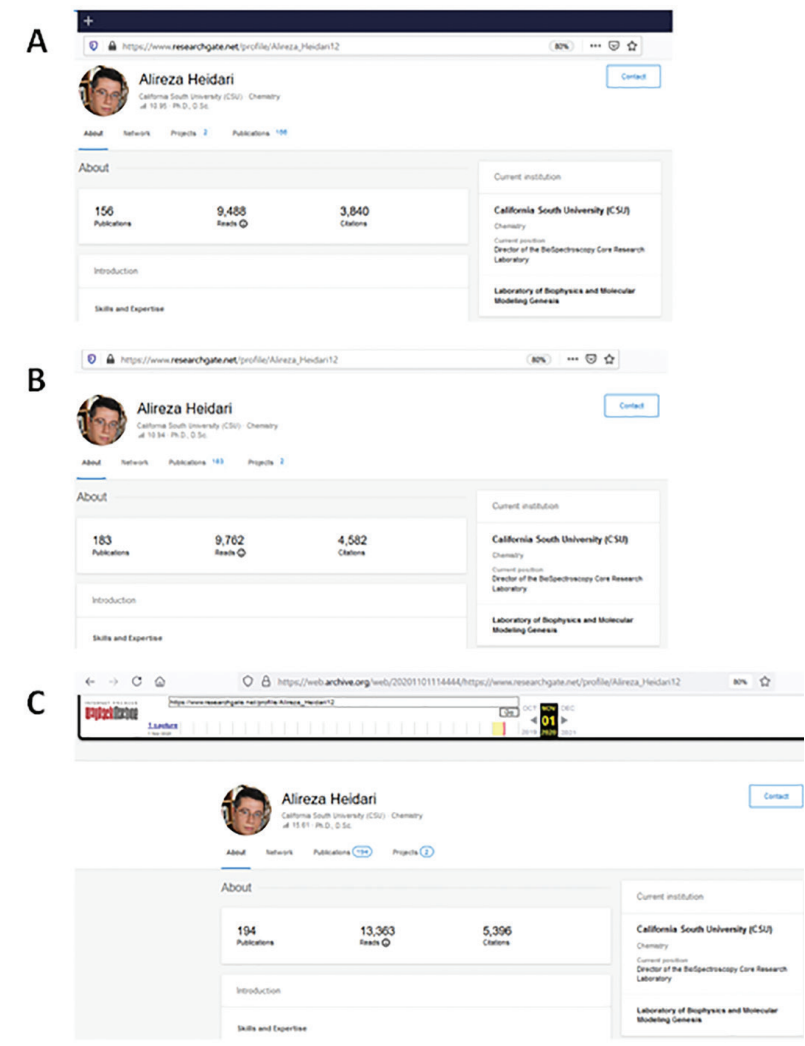


Table 1. ORCID accounts (10 examples) of "authors" with a "fruit"-related name, with improbable, unclear or suspect identity, all labelled as "No public information available", with no listed affiliation, and for which no academic paper associated with the ORCID ID could be identified on Google Scholar (search date: June 24, 2021). It is unclear how these "authors" achieve ORCID's goal of "Connecting research and researchers"

Searches 1-4: https://orcid.org/orcid-search/ search?searchQuery=fruit

Searches 5-6: https://orcid.org/orcid-search/ search?searchQuery=banana

Search 7: https://orcid.org/orcid-search/search?searchQuery=apple

Search 8: https://orcid.org/orcid-search/search?-
searchQuery=pear

Search 9: https://orcid.org/orcid-search/search?-

searchQuery=lemon

Search 10: https://orcid.org/orcid-search/search?-

searchQuery=watermelon

${ }^{1}$ The link from "Websites \& Social Links" leads to a website that appears to be associated with soccer/ sports betting, written in Indonesian

2 This "Lemon Lemon" could not be differentiated from other "Lemon Lemon" researchers (0000-0002-6586-856X, 0000-0001-6846-2955, 00000003-2586-8482), defeating the purpose of ORCID, namely to assign a unique numerical ID to a unique researcher.

${ }^{3}$ Although a company is listed for this entry, the first name and family name are clearly not names.

\begin{tabular}{|l|l|l|}
\hline \multicolumn{1}{|c|}{ ORCID ID (last modified date) } & \multicolumn{1}{|c|}{ First name } & \multicolumn{1}{|c|}{ Last name } \\
\hline$\underline{0000-0001-5205-2003}($ Oct 5,2020$)$ & fruit & salad \\
\hline$\underline{0000-0002-8303-1982}($ Jan 9, 2021) & Geofferey & Fruit \\
\hline$\underline{0000-0003-2239-703 X}($ Mar 9, 2021) & Côme & Fruit \\
\hline$\underline{0000-0002-4164-4297}($ Jul 9, 2018) & Juicy Fruit & Magsayo \\
\hline$\underline{0000-0001-6856-7917}($ Nov 26, 2019) & a & banana \\
\hline$\underline{0000-0002-0050-3340}($ May 29, 2021) & banana & Wu \\
\hline$\underline{0000-0003-0045-8524}($ Jun 14, 2019) & Apple & Pear \\
\hline$\underline{0000-0002-3963-3361}(\text { Jun 11, 2019) })^{1}$ & pear & pear \\
\hline$\underline{0000-0003-4825-0001}($ Dec 16, 2020) & Lemon & Lemon \\
\hline$\underline{0000-0002-8095-8643}($ Sep 10, 2020) & Eat Watermelon & Can Dogs \\
\hline
\end{tabular}

\section{Conflicts of interest}

The author has written about Retraction Watch and forbetterscience.com, blogs that are mentioned in this paper. In the former case, the author has been the subject of writing on that blog. The author declares no other conflicts of interest pertaining to the discussed topic.

\section{Acknowledgements}

The author thanks the feedback from Bahiyah Omar (Universiti Sains Malaysia, Malaysia) on an earlier version of the paper. The author also thanks the authentic Jamie F. Burr (College of Biological Science, University of Guelph, Canada) for discussion and clarification about his impersonator and identity theft case.

\section{CRediT roles}

Jaime A. Teixeira da Silva: conceptualization; formal analysis; investigation; methodology; project administration; supervision; validation; visualization; roles/writing - original draft; writing - review and editing. 


\section{References}

- Byrne, J. A., \& Christopher, J. (2020). Digital magic, or the dark arts of the $21^{\text {st }}$ century-how can journals and peer reviewers detect manuscripts and publications from paper mills?. FEBS Letters, 594(4), 583589. https://doi.org/10.1002/1873-3468.13747

- Collins, E.M., \& Bassat, Q. (2018). The scientific integrity of journal publications in the age of 'fake news'. Journal of Tropical Pediatrics, 64(5), 360-363. https://doi.org/10.1093/tropej/fmy039

- Dadkhah, M., Maliszewski, T., \& Teixeira da Silva, J.A. (2016). Hijacked journals, hijacked web-sites, journal phishing, misleading metrics and predatory publishing: actual and potential threats to academic integrity and publishing ethics. Forensic Science, Medicine, and Pathology, 12(3), 353-362. http://dx. doi.org/10.1007/s12024-016-9785-X

- Dal-Ré, R., Bouter, L.M., Cuijpers, P., Gluud, C., \& Holm, S. (2020). Should research misconduct be criminalized? Research Ethics, 16(1-2), 1-12. https:// doi.org/10.1177/1747016119898400

- Dony, C., Raskinet, M., Renaville, F., Simon, S., \& Thirion, P. (2020). How reliable and useful is Cabell's blacklist? A data-driven analysis. LIBER Quarterly, 30(1), 1-38. http://doi.org/10.18352/lq.10339

- Harvey, L. (2020). Research fraud: a long-term problem exacerbatedby the clamour for research grants. Quality in Higher Education, 26(3), 243-261. https://doi.org/10.1080/13538322.2020.1820126

- Hillman, J.R., \& Baydoun, E. (2019). Quality assurance and relevance in academia: a review. In: Badran, A., Baydoun, E., Hillman, J. (eds) Major Challenges Facing Higher Education in the Arab World: Quality Assurance and Relevance. Springer, Cham, Switzerland, pp. 13-68. https://doi.org/10.1007/9783-030-03774-1_2

- Hopf, H., Krief, A., Mehta, G., \& Matlin, S.A. (2019). Fake science and the knowledge crisis: ignorance can be fatal. Royal Society Open Science, 6, 190161. http://doi.org/10.1098/rsos.190161

- Horton, J., Kumar, D.K., \& Wood, A. (2020). Detecting academic fraud using Benford law: The case of Professor James Hunton. Research Policy, 49(8), 104084. https://doi.org/10.1016/j.respol.2020.104084 Kim, J., \& Owen-Smith, J. (2021). ORCID-linked labeled data for evaluating author name disambiguation at scale. Scientometrics, 126(3), 2057-2083. https:// doi.org/10.1007/s11192-020-03826-6

- Liu, B., Lin, L., Riazuddin, S., Zubair, A., Li, W.,
Di, L-J., Li, R., Dong, T-T., Deng, C-X., \& Tong, W-M. (2020). Retraction notice to "PP2ACa deficiency impairs early cortical development through inducing DNA damage in neuroprojenitor cells” [Int. J. Biochem. Cell Biol. 109C (2019) 40-58]. The International Journal of Biochemistry \& Cell Biology, 125, 105762. https://doi.org/10.1016/j.biocel.2020.105762

- Mallapaty, S. (2020). China bans cash rewards for publishing papers. Nature, 579(7797), 18. https://doi. org/10.1038/d41586-020-00574-8

- Manley, S. (2019). On the limitations of recent lawsuits against Sci-Hub, OMICS, ResearchGate, and Georgia State University. Learned Publishing, 32(4), 375-381. https://doi.org/10.1002/leap.1254

- Mavrogenis, A.F., Panagopoulos, G.N., Mauffrey, C., \& Scarlat, M.M. (2018). Fraud in publishing. In: Mauffrey C., Scarlat M. (eds) Medical Writing and Research Methodology for the Orthopaedic Surgeon. Springer, Cham, Switzerland, pp. 1-8. https:// doi.org/10.1007/978-3-319-69350-7_1

- Menon, V.G., \& Khosravi, M.R. (2019). Preventing hijacked research papers in fake (rogue) journals through social media and databases. Library $\mathrm{Hi}$ Tech News, 36(5), 1-6. https://doi.org/10.1108/LHTN11-2018-0070

- Noga-Styron, K.E., Olivero, J.M., \& Britto, S. (2016). Predatory journals in the criminal justices sciences: getting our cite on the target. Journal of Criminal Justice Education, 28(2), 174-191. https://doi.org/10.1080 /10511253.2016.1195421

- Oravec, J.A. (2019). The "dark side" of academics? Emerging issues in the gaming and manipulation of metrics in higher education. The Review of Higher Education, 42(3), 859-877. https://doi.org/10.1353/ rhe.2019.0022

- Pinna, N., Clavel, G., \& Roco, M.C. (2020). The Journal of Nanoparticle Research victim of an organized rogue editor network! Journal of Nanoparticle Research, 22(12), 376. https://doi.org/10.1007/s11051020-05094-0

- Rivera, H., \& Teixeira da Silva, J.A. (2021). Retractions, fake peer review, and paper mills. Journal of Korean Medical Science, 36(24), e165. https://doi. org/10.3346/jkms.2021.36.e165

- Samuel, A. J., \& Aranha, V. P. (2018). Valuable research in fake journals and self-boasting with fake metrics. Journal of Pediatric Neurosciences, 13(4), 517-518. https://doi.org/10.4103/JPN.JPN_66_18

- Teixeira da Silva, J.A. (2016a). Silent or stealth retractions, the dangerous voices of the unknown, de- 
leted literature. Publishing Research Quarterly, 32(1), 44-53. https://doi.org/10.1007/s12109-015-9439-y

- Teixeira da Silva, J.A. (2016b). The militarization of science, and subsequent criminalization of scientists. Journal of Interdisciplinary Medicine, 1(2), 214215. https://doi.org/10.1515/jim-2016-0031

- Teixeira da Silva, J.A. (2017a). Fake peer reviews, fake identities, fake accounts, fake data: beware! AME Medical Journal, 2, 28. http://dx.doi. org/10.21037/amj.2017.02.10

- Teixeira da Silva, J.A. (2017b). Are pseudonyms ethical in (science) publishing? Neuroskeptic as a case study. Science and Engineering Ethics, 23(6), 18071810. http://dx.doi.org/10.1007/s11948-016-9825-7

- Teixeira da Silva, J.A. (2020a). Is there a need for creators of imaginary authors to face legal consequences? Croatian Medical Journal, 61(6), 561-563. http://dx.doi.org/10.3325/cmj.2020.61.561

- Teixeira da Silva, J.A. (2020b). Failure of ORCID: 57 academics named "Beatriz". Update Dental College Journal, 10(2), 3-5. http://dx.doi.org/10.3329/updcj. v10i2.50172

- Teixeira da Silva, J.A. (2020c). Ethical considerations of the Andrra Qielli "sting” by Albana Berisha Qehaja. International Journal of Research in Business and Social Science, 9(6), 289-290. http://dx.doi. org/10.20525/ijrbs.v9i6.925

- Teixeira da Silva, J.A. (2020d). ORCID: a double-edged sword, and no silver bullet for science integrity. Annals of Library and Information Studies, 67(4), 246-250.

- Teixeira da Silva, J.A. (2020e). Are negative reviews, predatory reviewers or failed peer review rewarded at Publons? International Orthopaedics, 44(10), 2193-2194. http://dx.doi.org/10.1007/s00264020-04587-w

- Teixeira da Silva, J.A. (2020f). Is there a clear division between predatory and low-quality journals and publishers? Journal of the Royal College of Physicians of Edinburgh, 50(4), 458-459. http://dx.doi. org/10.4997/JRCPE.2020.303

- Teixeira da Silva, J.A. (2020g). An alert to COVID-19 literature in predatory publishing venues. The Journal of Academic Librarianship, 46(5), 102187. http:// dx.doi.org/10.1016/j.acalib.2020.102187

- Teixeira da Silva, J.A. (2021a). Paper mills and on-demand publishing: Risks to the integrity of journal indexing and metrics. Medical Journal Armed Forces India, 77(1), 119-120. http://dx.doi. org/10.1016/j.mjafi.2020.08.003
- Teixeira da Silva, J.A. (2021b). Abuse of ORCID’s weaknesses by authors who use paper mills. Scientometrics, 126(7), 6119-6125. http://dx.doi.org/10.1007/ s11192-021-03996-x

- Teixeira da Silva, J.A. (2021c). Non-compliance with ethical rules caused by misuse of ORCID accounts: implications for medical publications in the COVID-19 era. Ethics, Medicine and Public Health, 18, 100692. http://dx.doi.org/10.1016/j.jemep.2021.100692

- Teixeira da Silva, J.A. (2021d). What is a legitimate, low-quality, or predatory surgery journal? Indian Journal of Surgery (in press) http://dx.doi. org/10.1007/s12262-021-02730-4

- Teixeira da Silva, J.A. (2021e). Assessing the ethics of stings, including from the prism of guidelines by ethics-promoting organizations (COPE, ICMJE, CSE). Publishing Research Quarterly, 37(1), 90-98. http://dx.doi.org/10.1007/s12109-021-09784-y

- Teixeira da Silva, J.A. (2021f). Is the validity, credibility and reliability of literature indexed in PubMed at risk? Medical Journal Armed Forces India (in press) http://dx.doi.org/10.1016/j.mjafi.2021.03.009

- Teixeira da Silva, J.A., Al-Khatib, A. (2021). How do Clarivate Analytics and Publons propose to fortify peer review in the COVID-19 era? Journal of Taibah University Medical Sciences, 16(2), 139-143. http://dx. doi.org/10.1016/j.jtumed.2021.01.008

- Teixeira da Silva, J.A., \& Dobránszki, J. (2019). A new dimension in publishing ethics: social media-based ethics-related accusations. Journal of Information, Communication \& Ethics in Society, 17(3), 354-370. http://dx.doi.org/10.1108/JICES-05-2018-0051

- Teixeira da Silva, J.A., Dobránszki, J., Tsigaris, P., \& Al-Khatib, A. (2019). Predatory and exploitative behaviour in academic publishing: An assessment. The Journal of Academic Librarianship, 45(6), 102071. http://dx.doi.org/10.1016/j.acalib.2019. 102071

- Teixeira da Silva, J.A., \& Tsigaris, P. (2018). What value do whitelists and blacklists have in academia? The Journal of Academic Librarianship, 44(6), 781792. http://dx.doi.org/10.1016/j.acalib.2018.09.017

- Teixeira da Silva, J.A., \& Tsigaris, P. (2020). Issues with criteria to evaluate blacklists: An epidemiological approach. The Journal of Academic Librarianship, 46(1), 102070. http://dx.doi.org/10.1016/j.acalib.2019.102070

- Trapp, J. (2020). Predatory publishing, hijacking of legitimate journals and impersonation of researchers via special issue announcements: a warning for editors and authors about a new scam. Physical and 
Engineering Sciences in Medicine, 43(1), 9-10. https:// doi.org/10.1007/s13246-019-00835-5

- Tsigaris, P., \& Teixeira da Silva, J.A. (2021). Why blacklists are not reliable: A theoretical framework. The Journal of Academic Librarianship, 47(1), 102266. http://dx.doi.org/10.1016/j.acalib.2020.102266

- Umlauf, M.G., \& Mochizuki, Y. (2018). Predatory publishing and cybercrime targeting academics. International Journal of Nursing Practice, 24 (Suppl 1), e12656. http://dx.doi.org/10.1111/ijn.12656

- Utakrit, N., \& Wuttidittachotti, P. (2021). Possible attempts to identify e-mail header of the sender for academic qualification fraud. International Journal of Electronic Security and Digital Forensics, 13(1), 2852. https://doi.org/10.1504/IJESDF.2021.111719 Vasiu, I., \& Vasiu, L. (2019). Criminal copyright infringement: forms, extent, and prosecution in the United States. University of Bologna Law Review, 4(2), 229-260. https://doi.org/10.6092/issn.2531$6133 / 9782$

-Wjst, M. (2021). Scientific integrity is threatened by image duplications. American Journal Of Respiratory Cell and Molecular Biology, 64(2), 271-272. https:// doi.org/10.1165/rcmb.2020-0419LE

- Zhao, T-Y., Dai, T-C., Lun, Z-J., \& Gao, Y-L. (2021). An analysis of recently retracted articles by authors affiliated with hospitals in mainland China. Journal of Scholarly Publishing, 52(2), 107-122. https://doi. org/10.3138/jsp.52.2.03 